\title{
Schottky Diodes and Thin Films Based on Copolymer: Poly(aniline-co-toluidine)
}

\author{
A. Elmansouri, ${ }^{1}$ N. Hadik, ${ }^{1}$ A. Outzourhit, ${ }^{1}$ A. Lachkar, ${ }^{2}$ A. Abouelaoualim, ${ }^{1}$ M. E. Achour, ${ }^{3}$ \\ A. Oueriagli, ${ }^{1}$ and E. L. Ameziane ${ }^{1}$ \\ ${ }^{1}$ Laboratoire de Physique Solide et Couches Minces (LPSCM), Département de Physique, Faculté des Sciences Semlalia, BP 2390, \\ 40000 Marrakech, Morocco \\ ${ }^{2}$ LSM, Département de Chimie, Faculté des Sciences Semlalia, Marrakech, Morocco \\ ${ }^{3}$ LASTID, Département de Physique, Faculté des Sciences, Kenitra, Morocco
}

Correspondence should be addressed to A. Elmansouri, a.elmansouri@ucam.ac.ma

Received 14 April 2009; Accepted 28 July 2009

Recommended by Yalin Lu

\begin{abstract}
Poly(aniline-co-o-toluidine) (PANI-co-POT) thin films were deposited on indium tin oxide- (ITO-) coated glass substrates by electrochemical polymerization under cyclic voltammetric conditions from aniline-co-o-toluidine monomer in an aqueous solution of $\mathrm{HCl}$ as a supporting electrolyte. These measurements showed that the optical band gap of the copolymer films is on the order of $2.65 \mathrm{eV}$. On the other hand, ITO/PANI-co-POT/Al devices were fabricated by thermal evaporation of Aluminum circular electrodes on the as-deposited PANI-co-POT films. The Current-Voltage characteristics of these devices are nonlinear. The diode parameters were calculated from I-V characteristics using the modified Shockley equation. The C-F characteristics were also measured.
\end{abstract}

Copyright (C) 2009 A. Elmansouri et al. This is an open access article distributed under the Creative Commons Attribution License, which permits unrestricted use, distribution, and reproduction in any medium, provided the original work is properly cited.

\section{Introduction}

In recent years, considerable attention was given to the fabrication and characterization of thin films and Schottky diodes using conducting polymers as active materials. Intrinsically conducting polymers consisting of a $\pi$-conjugated backbone are attractive because of their unique electronic properties. As one of the most important conducting polymers, polyaniline and its derivatives have been extensively studied in different fields of science [1] because of the demand for highperformance materials in advanced technologies including microelectronic materials [2], rechargeable batteries [3], energy storage [4], sensors [5], photovoltaic cells [6], and actuators [7].

However, the common uses of polyaniline are restricted, due to its poor processability and low solubility. Various techniques, such as the modification of the monomer structure, the utilization of soluble precursor, and the preparation of copolymers and composites, have been introduced to enhance the processability and solubility. Indeed, the copolymerization has the advantage as the material obtained is homogenous and also the preparation methods are easy.

With regards to PANI-type copolymers, a pioneering work has been done by Wei et al. $[8,9]$. They have shown that aniline copolymerized with o-toluidine yields a homogenous copolymer film with controlled conductivity.

On the other hand, several authors [10-13] used various metal/polymer junctions with polyaniline and its derivatives to make and study Schottky barrier-type diodes. They estimated the electronic parameters such ideality factor, barrier height, and so forth. However, no studies have been performed on metal/(PANI-co-POT) junction.

In our series of papers [14-17], we have studied the electrical properties of Schottky diodes based on polyaniline, as well as polythiophene and its derivatives. In the present study, we report on the electrochemical and optical properties of PANI-co-POT films on one hand, and on the other hand, on the electrical properties of ITO/PANI-co-POT/Al junctions. 


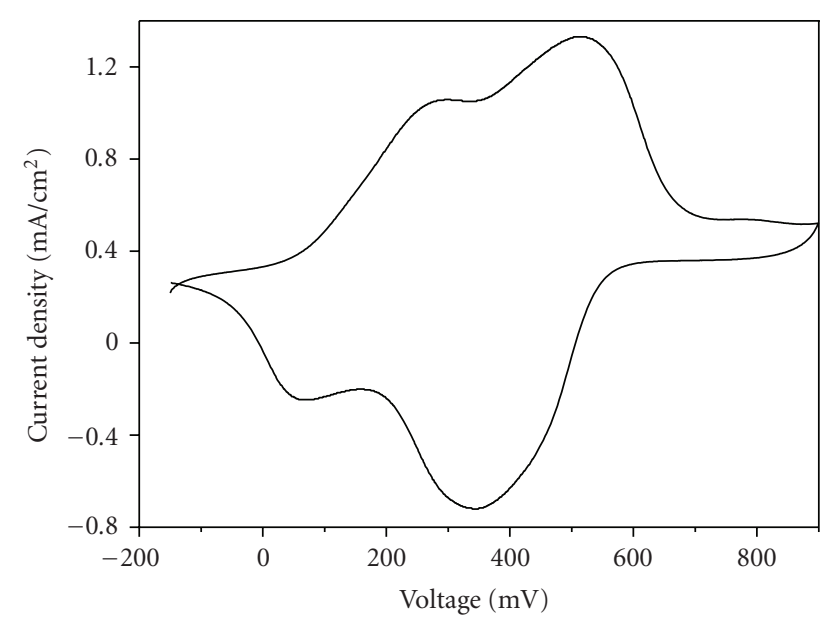

FIGURe 1: Cyclic voltammograms recorded during the synthesis of PANI-co-POT films.

\section{Experimental Procedure}

Poly(aniline-co-o-toluidine) (PANI-co-POT) films were electrochemically synthesized under cyclic voltammetric conditions [18]. Cyclic voltammetric studies were performed with a computer-controlled EG\&G Model 273A potensiostat-galvanostat. A three-electrode cell assembly was used during the electrochemical polymerization with an ITO-coated glass substrate as a working electrode, a Platinum foil as a counter electrode, and a Saturated Calomel Electrode (SCE) as a reference electrode. All the potentials are referenced with respect to the SCE. The ITOcoated glass substrates were ultrasound-cleaned in acetone and distilled water several times and subsequently airdried.

PANI-co-POT films were synthesized in aqueous solution of distilled o-toluidine and aniline $(0.1 \mathrm{M})$ in $\mathrm{HCl}$ $(0.5 \mathrm{M})$ solutions. To initiate the polymerization reaction, a fixed potential of $0.85 \mathrm{~V} / \mathrm{SCE}$ was first applied for three minutes. Subsequently, 40 cycles were performed for this sample by scanning the potential between -0.15 and $0.9 \mathrm{~V} / \mathrm{SCE}$ with a scan rate of $50 \mathrm{mV} / \mathrm{s}$. At the end of the fortieth cycle, the thin film is washed with the corresponding fresh electrolyte solution in order to remove the low molecular soluble products and then dried in ambient air.

The optical transmission of the as-electrodeposited PANI-co-POT films was measured using a Shimadzu-3101UVPC double-beam spectrophotometer in the wavelength range $400-900 \mathrm{~nm}$.

Schottky-barrier-type devices were fabricated by depositing $2 \mathrm{~mm}$ diameter circular aluminum electrodes on electropolymerized PANI-co-POT thin films. The aluminum was deposited in a separate vacuum chamber by thermal evaporation of $99.99 \%$ purity Aluminum shots for three minutes at base pressure of $1.5 \times 10^{-5} \mathrm{mbar}$.

The electrical measurements were performed on this ITO/PANI-co-POT/Al device at room temperature. The

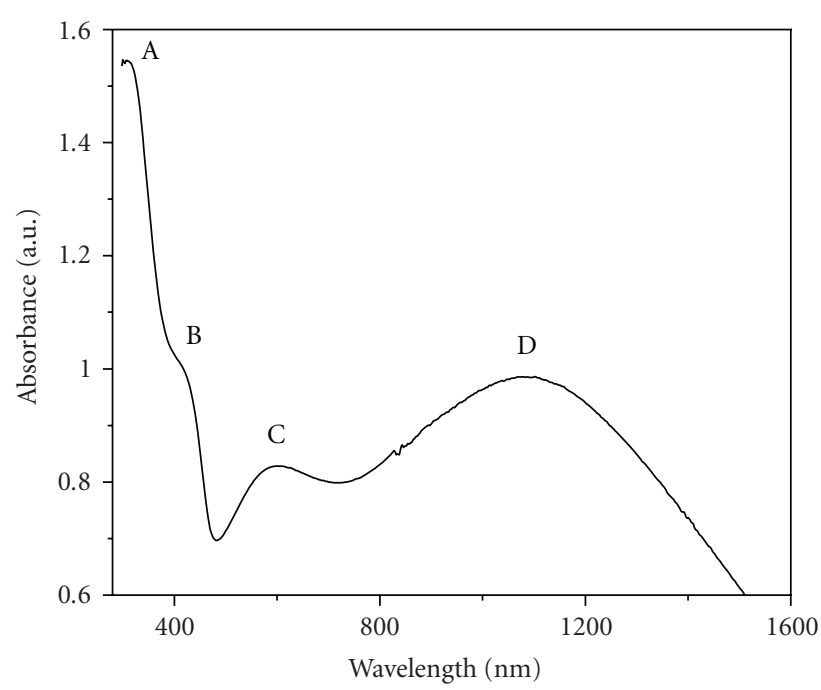

Figure 2: Optical absorption spectra of PANI-co-POT thin films.

current voltage characteristics were measured using a Keithly 410 programmable picoamperemeter and a $610 \mathrm{C}$ programmable microvoltmeter. The capacitance measurements were carried out using a Keithley LCZ3300 impedance meter. All the instruments are controlled by a computer via a GPIB card.

\section{Results and Discussion}

3.1. Electrochemical Characteristics of PANI-Co-POT. The 40th cyclic voltammograms recorded during the electrodeposition of the PANI-co-POT films on ITO-coated glass is presented in Figure 1. The voltammogram present two anodic peaks at 0.29 and $0.52 \mathrm{~V} / \mathrm{SCE}$. These peaks are usually assigned to the oxidization of PANI-co-POT films deposited on the working electrode, most likely the conversion of amine units to radical cations [19]. They correspond to the formation of radical cations (polaron formation in emeraldine form) from the leucoemeraldine form, and their oxidation to dications (bipolaron formation in pernigraniline form), respectively.

While taking account of the results reported in our work [14], the current density of oxidization peaks of (PANI-coPOT) is greater to those of the POT-homopolymer. This is in good agreement with literature [18]. Therefore, the thin films based on PANI-co-POT will be thicker than those based on POT alone.

Indeed, the introduction of polyaniline units permits to decrease the steric effects of the $-\mathrm{CH}_{3}$ groups and, therefore, to increase the conjugation and conductivity of the copolymer.

3.2. UV-Visible Absorption of the Electrodeposited PANI-CoPOT Films. Figure 2 shows typical UV-Visible absorption spectra of the PANI-co-POT. The spectra reveal the presence of several bands. 
(1) Sharp peak (A) centered at $308 \mathrm{~nm}$ which is attributed to the $\pi-\pi^{*}$ electronic transitions on the basis of the studies performed on polyanilines and theoretical band structure calculations [20]. This peak showed a shift relative to the corresponding transition in POT [14], thus revealing an increase in the conjugation length in PANI-co-POT as a result of copolymerization with PANI.

(2) Shoulder (B) at $426 \mathrm{~nm}$ can be assigned to the polaron generation, which suggests the protonation of the copolymer backbone (bipolaronic transition) occured.

(3) Hump (C) around $610 \mathrm{~nm}$ which represents the $n$ $\pi^{*}$ transition between the HOMO and the LUMO orbital [21].

(4) Broad peak (D) centered at $1080 \mathrm{~nm}$ which can be assigned to the polaronic transitions, suggesting the presence of the free carriers.

The optical band gap energy $\left(E_{g}\right)$ is obtained using the fundamental law [22]:

$$
\alpha(h v)=A\left(E_{g}-h v\right)^{n},
$$

where $\alpha$ is the absorption coefficient, $h v$ is the photon energy, $A$ is a proportionality constant, and $n=1 / 2$ for direct transitions. A similar value of $n=1 / 2$ was used by Huang et al. to calculate the band gap energy for substituted polyaniline [13]. $E_{g}$ can then be obtained by plotting $(\alpha h v)^{2}$ versus $(h v)$ (Figure 3 ) and extrapolating the linear fit to zero.

The allowed direct optical gap of the PANI-co-POT films is found to be on the order of $2.65 \mathrm{eV}$. This value is lower than that found in our previous work [14] for POT thin films. This is can be due to the effect of copolymerization with polyaniline which can permit to increase the degree of conjugation.

\subsection{Electrical Properties of ITO/PANI-Co-POT/Al Device}

3.3.1. Current-Voltage Characteristics. The I-V characteristics of the prepared ITO/POT-co-PANI/Al device are shown in Figure 4. This characteristic is nonlinear, asymmetric, and shows a rectifying behavior. This is further supported by the difference between the work function of PANI $(4.1 \mathrm{eV})$ and aluminum $(3.7 \mathrm{eV})[23]$.

The current transport across the polymer/metal junction is usually accounted for on the basis of thermoionic emission, Space-Charge Limited Current (SCLC), or PooleFrenkel emission $[24,25]$. The last two mechanisms are found not to be applicable for our diode in the exploited voltage range, as revealed by fitting their respective laws to experimental data. For the thermionic emission model, the I-V relationship is expressed by the modified Shockley equation [26]:

$$
I=I_{0}\left[\exp \left(\frac{q\left(V-R_{s} I\right)}{\eta k T}\right)-1\right],
$$

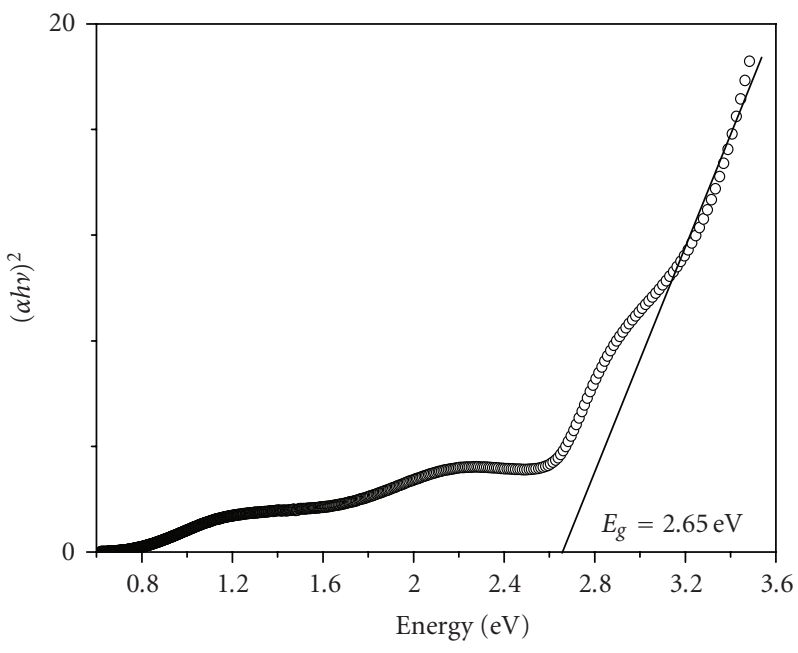

Figure 3: Plot of $(\alpha h v)^{2}$ versus $(h v)$.

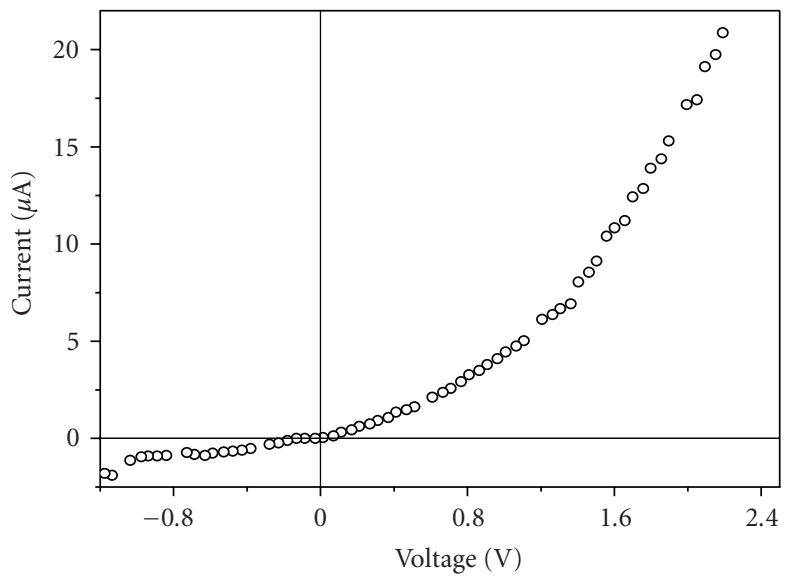

FIGURE 4: Current-voltage characteristics of ITO/PANI-co-POT/Al devices.

where $I_{0}$ is the saturation current, $q$ is the elementary charge (e), $V$ is the applied voltage, $k$ is the Boltzman constant, $\eta$ is the diode ideality factor, $R_{s}$ is the series resistance, and $T$ is the absolute temperature.

The saturation current is given by [27]

$$
I_{0}=A^{*} T^{2} \exp \left(-\frac{q \Phi_{B}}{k T}\right)
$$

where $A^{*}$ is the effective Richardson constant which depends on the effective mass of the carriers $\left(120 \mathrm{~A} \mathrm{~cm}^{-2} \mathrm{~K}^{-2}\right.$ for free carriers) and $\Phi_{B}$ is the barrier height.

As shown in Figure 5, this model accounts well for the experimental data over the explored voltage range in the forward bias region. The fit ((2) and (3)) yielded the following diode parameters: $\eta=22.1$, saturation current density $I_{0}=3.17 \times 10^{-5}\left(\mathrm{~A} / \mathrm{cm}^{2}\right), \Phi_{B}=0.68 \mathrm{eV}$, and $R_{s}=$ $2 \times 10^{4} \Omega$. These values are lower than those of ITO/POT/Al junction [14]. 


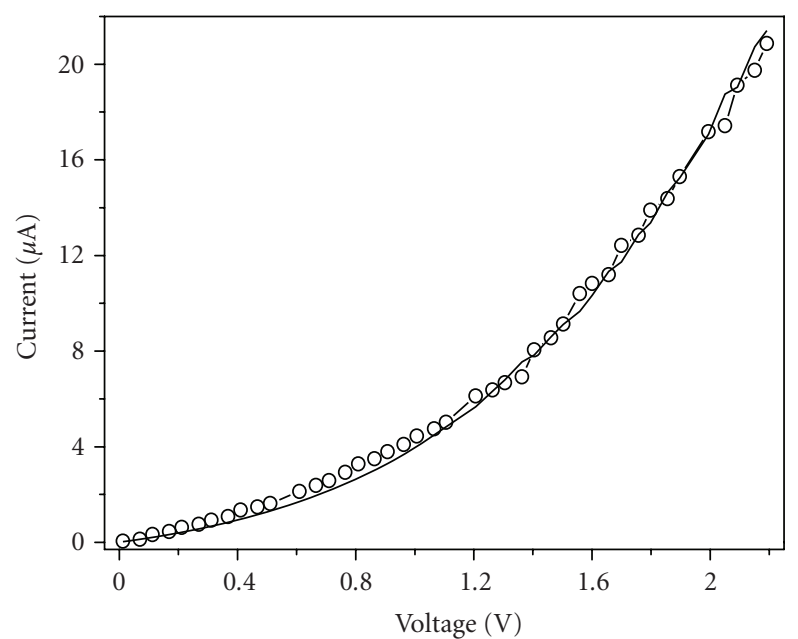

Figure 5: Experimental I-V characteristics of ITO/PANI-coPOT/Al device (o) and fit (line) using (2) and (3).

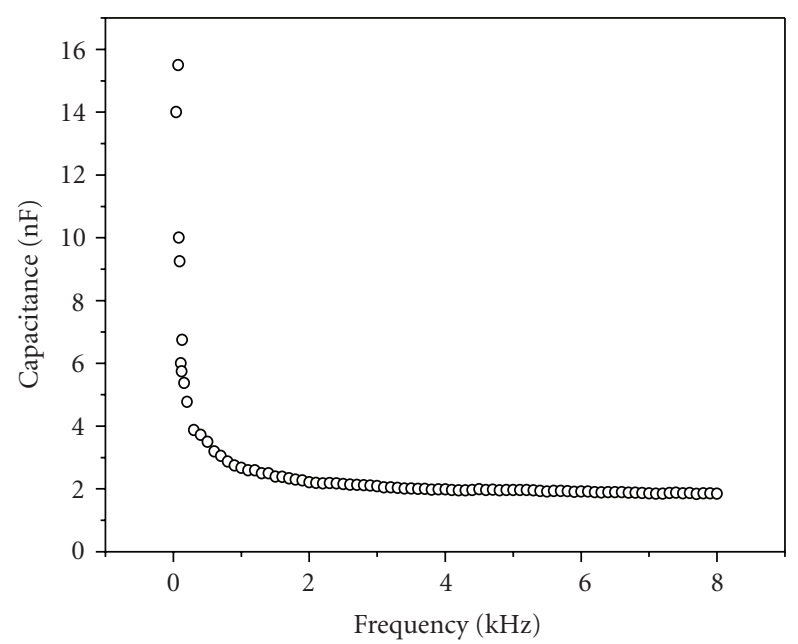

FIgURE 6: Capacitance-Frequency characteristics of ITO/PANI-coPOT/Al devices.

On the other hand, the value of the ideality factor of ITO/PANI-co-POT/Al Schottky device is greater than 1, but lower than that found by Saxena and Santhanam for the Schottky diodes based on a copolymer using poly(thiophene) [25]. This deviation of ideality factor from unity is generally attributed to the recombination of electrons and holes in the depletion region and/or the presence of barrier inhomogeneities, the reactive nature of the $\mathrm{Al}$ contact and trap assisted tunneling [28].

3.3.2. Capacitance-Frequency Characteristics. The zerobias capacitance-frequency (C-F) characteristics of the ITO/PANI-co-POT/Al diode are presented in Figure 6. The capacitance decreases as the measuring frequency is increased and then stabilizes. Such a frequency dispersion of the capacitance suggests the presence of a distribution of localized states in the band gap of the amorphous polymer [29].
In addition, the capacitance of the ITO/PANI-co-POT/Al diode is lower than that of the ITO/POT/Al diode presented in our previous work [14]. This reflects an increase in the film thickness by the copolymerization of the POT with PANI, which is in good agreement with UV-Vis spectroscopy and cyclic voltametry results.

\section{Conclusion}

We have successfully deposited PANI-co-POT thin films on ITO-coated glass by cyclic voltammetry methods. ITO/PANI-co-POT/Al sandwich devices were also fabricated based on these films. The optical gaps of the obtained PANIco-POT films are lower than those for POT thin films. The cyclic voltammetric investigation indicated that the current density of oxidization peaks of (PANI-co-POT) are greater to those of the POT- homopolymer.

On the other hand, the I-V characteristics of ITO/PANIco-POT/Al diodes showed a rectifying behavior. The electronic parameters of the diodes are determined using the modified Shockely equation. The C-F measurements suggest a distribution of localized states in the band gap of the polymer.

\section{References}

[1] A. B. Sanghvi, K. P. H. Miller, A. M. Belcher, and C. E. Schmidt, "Biomaterials functionalization using a novel peptide that selectively binds to a conducting polymer," Nature Materials, vol. 4, no. 6, pp. 496-502, 2005.

[2] J. L. Boehme, D. S. K. Mudigonda, and J. P. Ferraris, "Electrochromic properties of laminate devices fabricated from polyaniline, poly(ethylenedioxythiophene), and poly $(\mathrm{N}-$ methylpyrrole)," Chemistry of Materials, vol. 13, no. 12, pp. 4469-4472, 2001.

[3] G. D. Sharma, S. K. Sharma, and M. S. Roy, "Photovoltaic properties of Schottky device based on dye sensitized poly (3phenyl azo methine thiophene) thin film," Thin Solid Films, vol. 468, no. 1-2, pp. 208-215, 2004.

[4] A. G. MacDiarmid, S.-L. Mu, N. L. D. Somasiri, and W. Wu, "Electrochemical characteristics of "polyaniline" cathodes and anodes in aqueous electrolytes," Molecular Crystals and Liquid Crystals, vol. 121, pp. 187-190, 1985.

[5] B. Qi, W. Lu, and B. R. Mattes, "Strain and energy efficiency of polyaniline fiber electrochemical actuators in aqueous electrolytes," Journal of Physical Chemistry B, vol. 108, no. 20, pp. 6222-6227, 2004.

[6] P. Camurlu, A. Cirpan, and L. Toppare, "Dual type complementary colored polymer electrochromic devices utilized by 3-ester substituted thiophenes," Journal of Electroanalytical Chemistry, vol. 572, no. 1, pp. 61-65, 2004.

[7] H. S. Kolla, S. P. Surwade, X. Zhang, A. G. MacDiarmid, and S. K. Manohar, "Absolute molecular weight of polyaniline," The Journal of the American Chemical Society, vol. 127, no. 48, pp. 16770-16771, 2005.

[8] Y. Wei, W. W. Focke, G. E. Wnek, A. Ray, and A. G. MacDiarmid, "Synthesis and electrochemistry of alkyl ringsubstituted polyanilines," Journal of Physical Chemistry, vol. 93, no. 1, pp. 495-499, 1989. 
[9] Y. Wei, R. Hariharan, and S. A. Patel, "Chemical and electrochemical copolymerization of aniline with alkyl ringsubstituted anilines," Macromolecules, vol. 23, no. 3, pp. 764758, 1990.

[10] S. Carrara, V. Bavastrello, M. K. Ram, and C. Nicolini, "Nanometer sized polymer based Schottky junctions," Thin Solid Films, vol. 510, no. 1-2, pp. 229-234, 2006.

[11] R. A. Nafdey and D. S. Kelkar, "Diode using FeCl3-doped polyaniline," Thin Solid Films, vol. 477, no. 1-2, pp. 95-99, 2005.

[12] R. K. Gupta and R. A. Singh, "Fabrication and characteristics of Schottky diode based on composite organic semiconductors," Composites Science \& Technology, vol. 65, no. 3-4, pp. 677-681, 2005.

[13] L.-M. Huang, T. Chen Wen, A. Gopalan, and F. Ren, "Structural influence on the electronic properties of methoxy substituted polyaniline/aluminum Schottky barrier diodes," Materials Science and Engineering B, vol. 104, no. 1-2, pp. 88 95, 2003.

[14] A. Elmansouri, A. Outzourhit, A. Lachkar, et al., "Influence of the counter ion on the properties of poly(o-toluidine) thin films and their Schottky diodes," Synthetic Metals, vol. 159, no. 3-4, pp. 292-297, 2008.

[15] A. Elmansouri, A. Outzourhit, A. Oueriagli, et al., "Spectroscopic characterization of electrodeposited poly(otoluidine) thin films and electrical properties of ITO/poly(otoluidine)/aluminum Schottky diodes," Active and Passive Electronic Components, vol. 2007, Article ID 17846, 7 pages, 2007.

[16] S. Tagmouti, A. Outzourhit, A. Oueriagli, et al., "Electronic properties of poly(3-methylthiophene)," Solar Energy Materials and Solar Cells, vol. 71, no. 1, pp. 9-18, 2002.

[17] S. Tagmouti, A. Outzourhit, A. Oueriagli, et al., "Electrical characteristics of W/P3MT/Pt diodes," Thin Solid Films, vol. 379, no. 1-2, pp. 272-278, 2000.

[18] D. D. Borole, U. R. Kapadi, P. P. Kumbhar, and D. G. Hundiwale, "Influence of inorganic and organic supporting electrolytes on the electrochemical synthesis of polyaniline, poly(o-toluidine) and their copolymer thin films," Materials Letters, vol. 56, no. 5, pp. 685-691, 2002.

[19] W.-S. Huang, B. D. Humphrey, and A. G. MacDiarmid, "Polyaniline, a novel conducting polymer. Morphology and chemistry of its oxidation and reduction in aqueous electrolytes," Journal of the Chemical Society, Faraday Transactions, vol. 82, pp. 2385-2400, 1986.

[20] A. Pron and P. Rannou, "Processible conjugated polymers: from organic semiconductors to organic metals and superconductors," Progress in Polymer Science, vol. 27, no. 1, pp. 135190, 2002.

[21] A. A. Athawale, M. V. Kulkarni, and V. V. Chabukswar, "Studies on chemically synthesized soluble acrylic acid doped polyaniline," Materials Chemistry and Physics, vol. 73, no. 1, pp. 106-110, 2002.

[22] J. Tauc, Ed., Amorphous and Liquid Semiconductors, Plenum Press, London, UK, 1974.

[23] S.-A. Chen and Y. Fang, "Polyaniline schottky barrier: effect of doping on rectification and photovoltaic characteristics," Synthetic Metals, vol. 60, no. 3, pp. 215-222, 1993.

[24] R. Gupta, S. C. K. Misra, B. D. Malhotra, N. N. Beladakere, and S. Chandra, "Metal/semiconductive polymer Schottky device," Applied Physics Letters, vol. 58, no. 1, pp. 51-52, 1991.
[25] V. Saxena and K. S. V. Santhanam, "Junction properties of Schottky diode with chemically prepared copolymer having hexylthiophene and cyclohexylthiophene units," Current Applied Physics, vol. 3, no. 2-3, pp. 227-233, 2003.

[26] A. L. Fahrenbruch and R. H. Bube, Fundamentals of Solar Cells: Photovoltaic Solar Energy Conversion, Academic Press, New York, NY, USA, 1983.

[27] G. D. Storrier, S. B. Colbran, and D. B. Hibbert, "Chemical and electrochemical syntheses, and characterization of poly(2,5dimethoxyaniline) (PDMA): a novel, soluble, conducting polymer," Synthetic Metals, vol. 62, no. 2, pp. 179-186, 1994.

[28] B. Fabre, G. P. Lopinski, and D. D. M. Wayner, "Photoelectrochemical generation of electronically conducting polymerbased hybrid junctions on modified si(111) surfaces," Journal of Physical Chemistry B, vol. 107, no. 51, pp. 14326-14335, 2003.

[29] P. Viktorovitch, "Interpretation of the conductance and capacitance frequency dependence of hydrogenated amorphous silicon Schottky barrier diodes," Journal of Applied Physics, vol. 51, no. 9, pp. 4847-4854, 1980. 

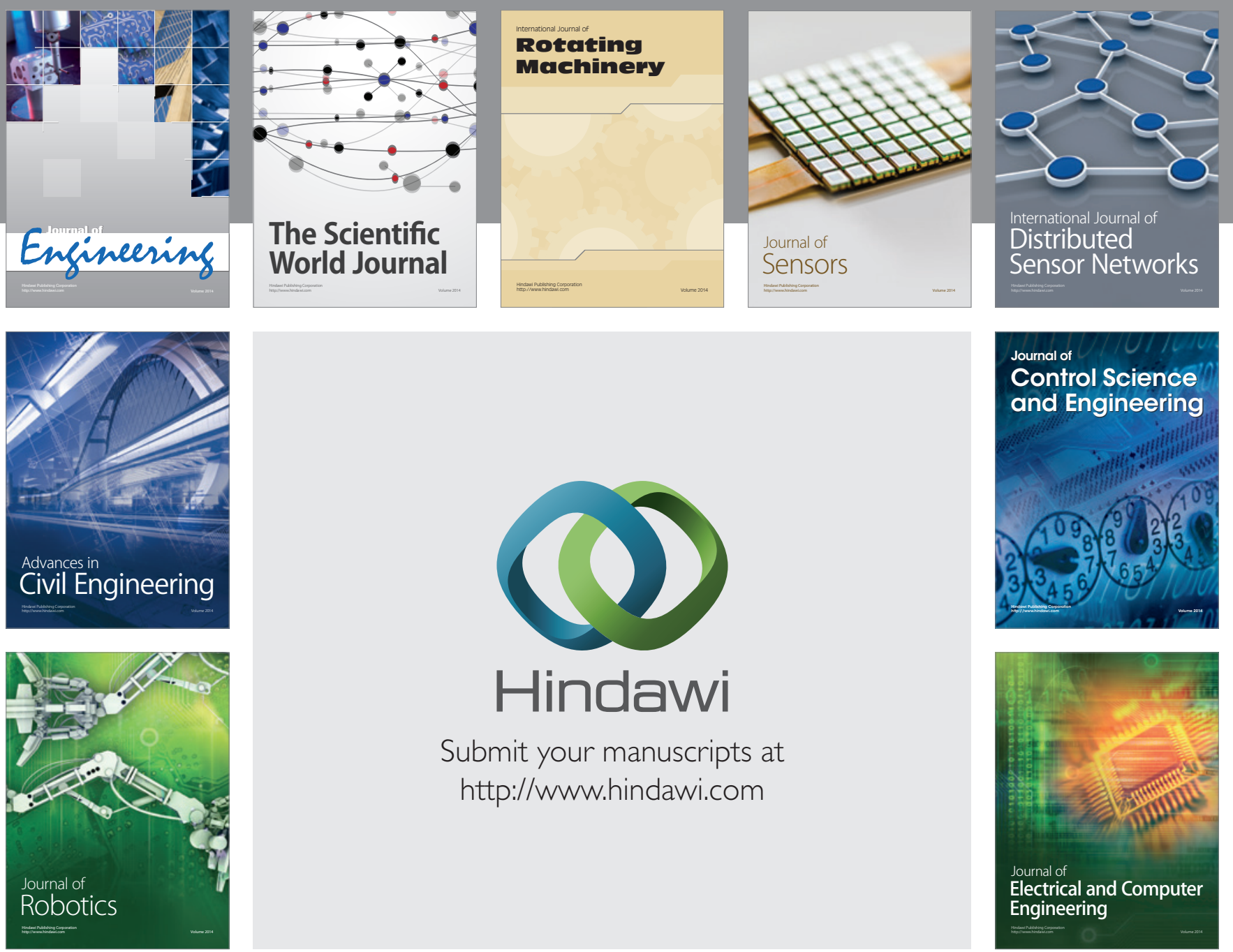

Submit your manuscripts at

http://www.hindawi.com
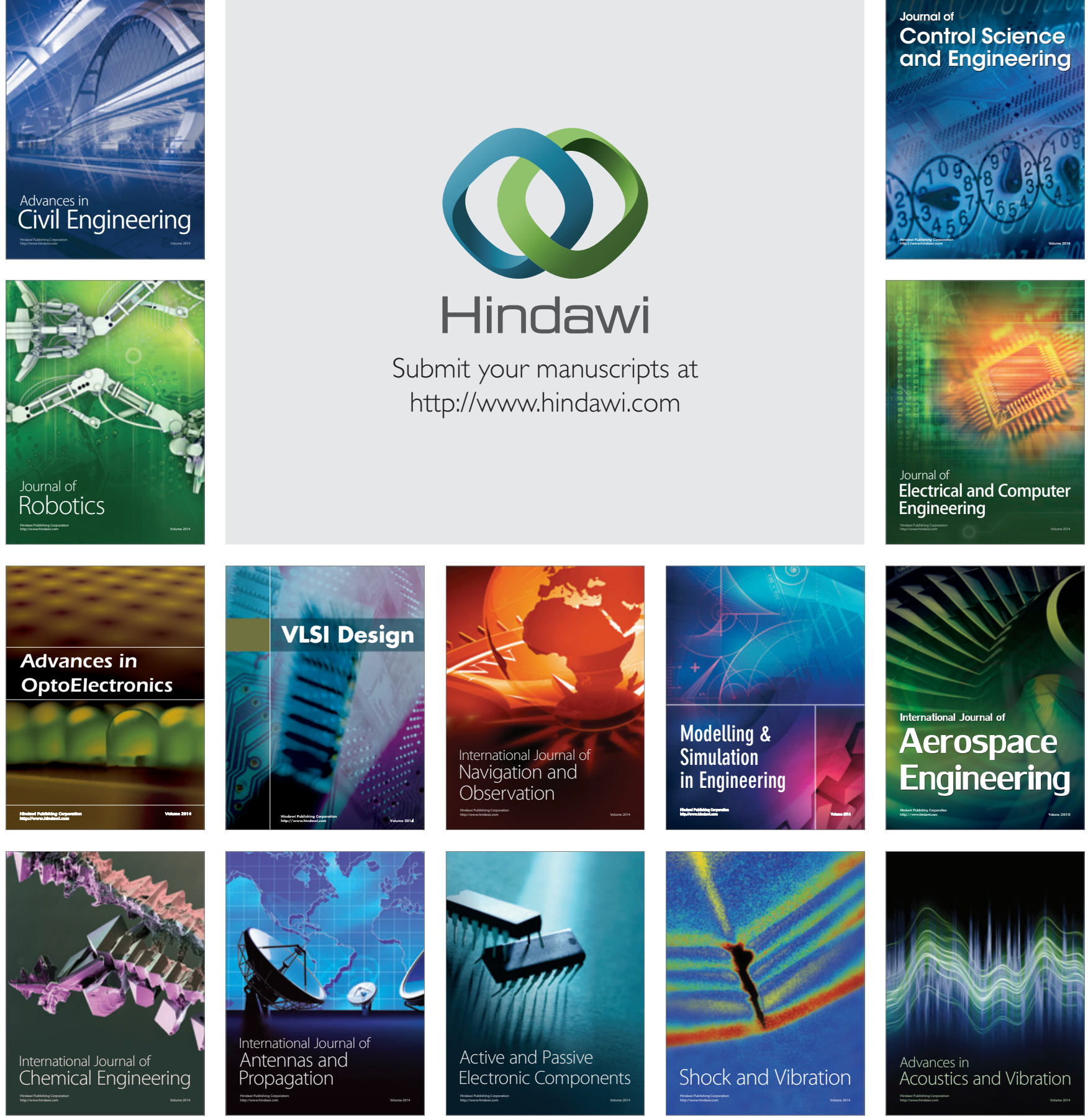